\section{Perfil epidemiológico da coqueluche no Rio Grande do Sul, Brasil: estudo da correlação entre incidência e cobertura vacinal}

\author{
Epidemiological profile of pertussis in Rio Grande \\ do Sul State, Brazil: a study of the correlation \\ between incidence and vaccine coverage
}

\author{
1 Escola de Enfermagem, \\ Universidade Federal do \\ Rio Grande do Sul, Brasil. \\ Correspondência \\ S. Trevizan \\ Escola de Enfermagem, \\ Universidade Federal do \\ Rio Grande do Sul. \\ Rua General João Telles 215, \\ apto. 302, Porto Alegre, RS \\ 90035-121, Brasil. \\ sarinatrevizan@yahoo.com.br
}

\begin{abstract}
An upward trend was observed in pertussis incidence in the State of Rio Grande do Sul, Brazil, since 2000, leading to an epidemic alert in 2004, based on epidemiological bulletins issued by government health agencies. Our objective in the current study was to identify the epidemiological profile of pertussis in the State. We used the incidence of reports of the disease from January 1995 to December 2004, the percentage of vaccine coverage, and characterization of the affected population. A control diagram was constructed to determine the magnitude of the disease in 2004. To analyze the correlation between incidence and vaccine coverage, we established the fluctuation between the vaccine coverage and case reporting in the last ten years. In Rio Grande do Sul, pertussis was on an epidemic level in 2004, representing an important cause of morbidity and mortality in infants (< l year), despite the availability of effective vaccines and high vaccine coverage rates in recent years. Studies are thus needed on the disease pattern in the coming years in order to determine the factors involved in this resurgence.
\end{abstract}

Whooping Cough; Immunization Coverage; Communicable Diseases
Sarina Trevizan 1

Simone Elizabeth Duarte Coutinho 1

\section{Introdução}

Uma brusca redução na ocorrência da coqueluche no mundo ocorreu após a introdução do uso da vacina contra esta doença. Acreditava-se que com a sistemática utilização em larga escala da imunização anti-pertussis a incidência na população permaneceria em níveis baixos, toleráveis ou até mesmo poderia ser considerada erradicada, no entanto, o que se observa é o ressurgimento da doença em locais de alta incidência da cobertura vacinal.

Estima-se a ocorrência anual global de $50 \mathrm{mi}$ lhões de casos e mais de 300 mil mortes provocadas pela doença ${ }^{1}$. No Brasil, são notificados em média 2 mil casos por ano 2 . As crianças menores de um ano de idade, especialmente com menos de seis meses, são o grupo que apresenta taxas de incidência e letalidade mais acentuadas 3 .

Vários países, tanto desenvolvidos quanto em desenvolvimento, informaram taxas crescentes de coqueluche 4,5 . Naqueles em desenvolvimento a dificuldade está em alcançar e manter alta cobertura vacinal. Já nos desenvolvidos, cuja cobertura vacinal é alta, como Austrália, Canadá, Estados Unidos e França, a partir da década de 80 , após trinta anos de controle houve um aumento da doença em todas as faixas etárias, até mesmo nos imunizados, devido a uma mudança no padrão de infecção 5,6,7 .

Algumas hipóteses apontadas para o ressurgimento da doença foram a perda gradual da 
imunidade adquirida, mudanças genéticas da bactéria, o aumento do número de portadores assintomáticos e a seleção natural de variantes resistentes à vacina, podendo ainda haver uma combinação de outros fatores como uso de novos métodos diagnósticos e melhoria dos sistemas de vigilância epidemiológica 5,8.

No Brasil, foi iniciado em 1983 o uso sistemático da vacina tríplice bacteriana (DTP) que protege contra a coqueluche, além da difteria e tétano, tornando-se passível de medidas de controle e prevenção eficazes ${ }^{9}$. Portanto, a reemergência da coqueluche no Brasil é uma possibilidade que merece atenção dos serviços de vigilância e controle de doenças, já que em países desenvolvidos o aumento dos casos se deu cerca de trinta anos após o início da imunização em massa 5 .

Atualmente, o Ministério da Saúde preconiza cobertura vacinal para DTP acima de $90 \%$ dos suscetíveis, e atribui eficácia de $75 \%$ a $80 \%$ contra a coqueluche com esquema básico completo 10 . Dados de incidência precisos são difíceis de apurar devido às subnotificações e subdiagnósticos, principalmente em crianças maiores e adultos cuja apresentação da doença pode ser atípica 3 . Em 2001, foi atingido índice de cobertura vacinal de $97 \%$, porém com valores heterogêneos entre os estados brasileiros 2 . Somente $64 \%$ dos municípios brasileiros alcançaram a meta de vacinação para DTP em menores de um ano de idade, em atividades de rotina em $2002^{9}$. No Rio Grande do Sul, Brasil, a cobertura vacinal referente ao ano de 2004 foi de $74,99 \%$, sendo que para a tetravalente (DTP + Hib) é de 98,24\% 11 .

Foram confirmados 1.236, 835, 663, 1.045 casos da doença no Brasil e 3, 35, 45, 71 no Rio Grande do Sul, em 2000, 2001, 2002, 2003, respectivamente 11. Porém, somente em Porto Alegre, em janeiro e fevereiro de 2004 foram notificados 17 casos de coqueluche, enquanto o total de casos nos anos de 1998, 1999, 2001, 2002, 2003 foram 3, $18,46,21$ e 15 casos, respectivamente 12 . No total, em 2004 foram notificados 156 casos suspeitos e 91 confirmados, sendo 61 residentes no município. A partir desse cenário, a coqueluche deixou de ser um agravo de notificação simples, passando a requerer investigação epidemiológica em Porto Alegre ${ }^{8}$.

Frente ao cenário do Município de Porto Alegre e ampliando a esfera de análise, propomos, por meio da investigação do perfil epidemiológico dos casos de coqueluche no Estado do Rio Grande do Sul, descrever a proporção da ocorrência da doença nesta população, determinando se está em nível endêmico ou epidêmico num paralelo em relação à situação vacinal da população afetada.

\section{Material e métodos}

Trata-se de um estudo epidemiológico descritivo em série histórica.

A população utilizada abrange todos os casos notificados e/ou confirmados de coqueluche no Estado do Rio Grande do Sul, registrados no Sistema Nacional de Agravos de Notificação (SINAN) no período de janeiro de 1995 a dezembro de 2004.

Os dados secundários utilizados referentes à ocorrência de casos de coqueluche e cobertura vacinal foram coletados nos registros de informação da Secretária Estadual de Saúde do Rio Grande do Sul, na própria sede (Departamento de Vigilância Epidemiológica), na página eletrônica (http://www.saude.rs.gov.br), na base de dados do Sistema Nacional de Vigilância Epidemiológica do Ministério da Saúde e Departamento de Informática do SUS (DATASUS; http:/ / www.datasus.gov.br). Os dados populacionais foram pesquisados na página eletrônica do Instituto Brasileiro de Geografia e Estatística (IBGE; http://www.ibge.gov.br).

A ferramenta utilizada para a análise da situação epidemiológica em 2004 foi a construção do diagrama de controle. Para tal, foi empregando o cálculo da média dos casos na determinação do limiar endêmico, em períodos mensais num histórico de dez anos, sendo excluídos os anos de maior e de menor incidência para que a série não sofresse influência de valores aberrantes, acarretando vieses no diagrama 13,14.

Conforme a literatura específica foi selecionado um período de dez anos, de 1995 a 2004, em função da disponibilidade de dados e por representarem a situação epidemiológica mais recente. Para a construção da faixa endêmica, ou seja, a faixa de valores esperados para cada mês, foi calculada a média do número de casos notificados, mensalmente, e o desvio padrão para cada mês. O limite máximo do diagrama foi construído com os valores obtidos pela soma de 1,96 desvio-padrão aos valores médios mensais e o limite mínimo do diagrama com os valores obtidos pela subtração de 1,96 desvio-padrão dos valores médios mensais 13 .

Essa concepção baseia-se no modelo da curva normal, e o intervalo considerado endêmico representa $95 \%$ do espaço da curva normal. Dessa forma, ficam estabelecidos os níveis endêmicos, ou seja, as variações atribuídas à normalidade 14 . Assim, os valores ou qualquer ocorrência que ultrapasse o limite máximo são considerados uma epidemia; os abaixo representam controle da doença 15 .

A análise da correlação entre incidência da coqueluche e cobertura vacinal foi estabelecida 
através da flutuação entre a curva da cobertura vacinal comparada à curva do número de casos notificados nos últimos dez anos. Conforme já relatado, há uma tendência definida à diminuição da incidência associada ao incremento dos índices de cobertura vacinal 16.

\section{Resultados}

No ano de 2004, no Rio Grande do Sul, foram notificados 442 casos suspeitos de coqueluche. Quando comparamos esses dados aos dos anos anteriores, observamos uma elevação brusca do número de casos notificados ao sistema de vigilância no estado nos últimos anos (Figura 1). Observa-se também que a partir de 1998 o número de casos mantinha-se numa tendência decrescente, chegando à notificação de 71 agravos no ano 2000. Desde então o panorama mudou: as notificações progressivamente aumentaram, atingindo o cume de 442 em 2004. Semelhante à tendência da notificação de casos, o valor mínimo de agravos confirmados foi no ano $2000 \mathrm{com}$ 3 casos, e o valor máximo e elevado em 2004 com 245, como ilustrado na Figura 1.

Em relação à procedência dos casos notificados em 2004, houve uma concentração na Região Metropolitana de Porto Alegre com 58\%. É importante destacar a publicação de um alerta epidemiológico em fevereiro de 2004, pela Secretaria Municipal de Saúde de Porto Alegre para todos os serviços de saúde da cidade, sobre o aumento da notificação de casos isolados ou surtos familiares em residentes de Porto Alegre e região metropolitana no final de 2003 e início de 2004. Assim, uma parcela do aumento de casos e concentração da notificação pode ter sido decorrente da resposta da vigilância com a publicação do alerta.

Em 2004, dos 442 casos notificados no Rio Grande do Sul, 245 (55\%) foram confirmados. É sabido que o Rio Grande do Sul conta com apenas um laboratório de referência, o Laboratório Central de Saúde Pública do Estado do Rio Grande do Sul, do Instituto de Pesquisas Biológicas, disponibilizado a partir de junho de 2004 para realização da cultura da Bordetella pertussis. Esse método é considerado padrão-ouro para o diagnóstico de coqueluche e o único critério de confirmação laboratorial aceito atualmente pelo Ministério da Saúde ${ }^{3}$. No entanto, pela escassez desse recurso no Estado do Rio Grande do Sul, mesmo que ainda que não esteja contemplada entre os critérios de confirmação de casos preconizados pelo Ministério da Saúde, em Porto Alegre a técnica de reação em cadeia de polimerase (polymerase chain reaction - PCR) é aceita pela equipe de vigilância municipal para confirmação
Figura 1

Casos de coqueluche. Rio Grande do Sul, Brasil, 1997-2004.

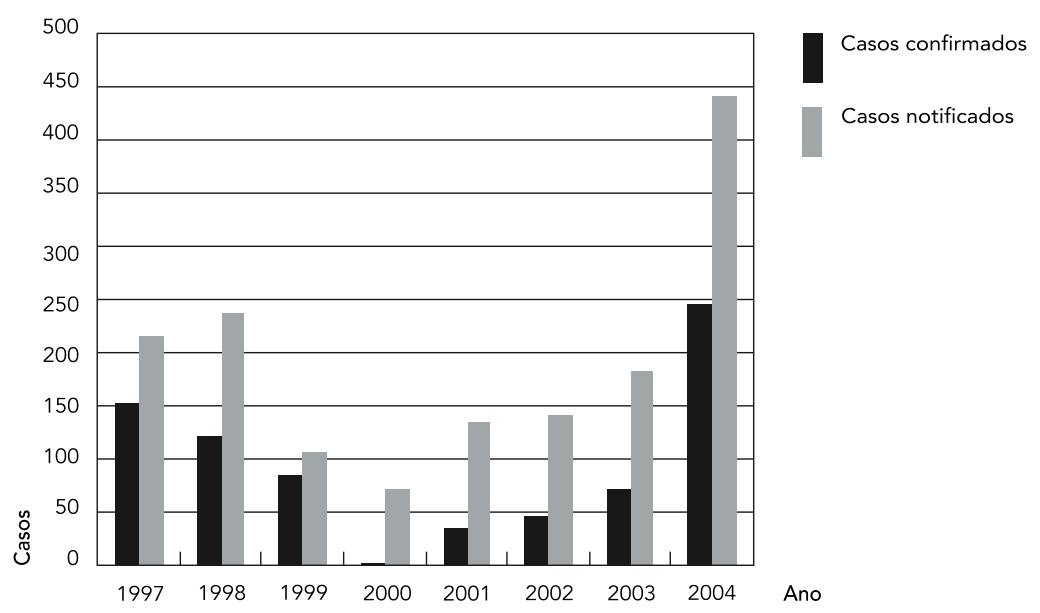

Fonte: Sistema Nacional de Agravos de Notificação (SINAN)/Departamento de Vigilância Epidemiológica/Secretária Estadual de Saúde do Rio Grande do Sul.

de caso ${ }^{8}$, já que esta técnica é realizada por três laboratórios (um público e dois privados).

Apesar da solicitação à Secretária Estadual de Saúde do Rio Grande do Sul, até o momento do fechamento dos dados não nos foram informados quais os critérios de confirmação utilizados para cada caso nem a situação vacinal dos casos confirmados no estado. Assim, trabalhamos com a população referente ao Município de Porto Alegre, já que este foi responsável por cerca de 61 casos (25\%) daqueles confirmados no Rio Grande do Sul em 2004.

Desse modo, a confirmação de casos deu-se em $26 \%$ por critério clínico, $25 \%$ por leucograma, $23 \%$ por vínculo epidemiológico, $18 \%$ por PCR e $8 \%$ por cultura. Dos 61 casos confirmados, 11 tinham recebido uma dose da vacina (18\%), 8 com duas doses (13\%), 4 com três doses da vacina (7\%), 13 com as três doses mais dose de reforço (21\%), 14 não haviam recebido nenhuma dose da vacina (23\%) e em 11 a situação vacinal era ignorada (18\%). No entanto, nenhum dos 13 casos cujo esquema vacinal foi considerado completo, foi confirmado por testes específicos contra a coqueluche, ou seja, cultura bacteriológica e PCR 8. Sugerindo que a vacina utilizada confere proteção contra a bactéria circulante na comunidade. Ao mesmo tempo, é possível supor que a maioria dos casos confirmados da doença ocorre em indivíduos não imunizados ou com esquema 
vacinal incompleto, reiterando a maior suscetibilidade à doença nestes casos 17,18.

Em 2004, no Rio Grande do Sul, dos 442 casos notificados, 299 foram observados em crianças menores de 1 ano (67\%), de 1 a 4 anos foram 74 (17\%), de 5 a 9 foram 39 (9\%), de 10 a 19 foram 10 (2\%) e a partir dos 20 anos foram notificados 20 casos (5\%).

Assim, em relação à distribuição de casos por faixas etárias, o grupo de idade mais atingido e de maior risco para a coqueluche é o de menores de um ano. Esses percentuais também demonstram uma pequena proporção da ocorrência da doença entre adolescentes e adultos, contrastando com o que vem sendo descrito na literatura atual, pois uma das explicações plausíveis para o aumento de casos entre as crianças pequenas em populações com coberturas vacinais elevadas é a ocorrência da doença em indivíduos mais velhos, que serviriam como fonte de transmissão, mantendo a bactéria circulante na comunidade 19 . Isso realmente pode estar acontecendo, porém pelas inúmeras dificuldades diagnósticas relacionadas à própria doença, esses casos podem não ser captados pelos sistemas de vigilância.
Analisando a notificação da doença nas demais faixas etárias nos últimos anos no Rio Grande do Sul (Figura 2), observa-se uma tendência de aumento em todas as idades, porém também mais acentuada entre os menores de um ano.

A maior concentração de casos na faixa etária de menores de um ano é esperada, já que este é o grupo de risco clássico. No entanto, esse aumento dos casos nesse grupo sugere entre outras possibilidades que esta suscetibilidade pode estar sendo agravada pelo aumento da população suscetível nas demais faixas etárias, considerando que a imunidade diminui com o passar dos anos 19,20,21.

No entanto, refletindo sobre a ocorrência por faixas etárias informadas no Rio Grande do Sul, não é possível identificar o padrão de distribuição semelhante ao que atualmente está sendo observado em países com coberturas vacinais elevadas. Segundo a literatura internacional, além do número aumentado da coqueluche em lactentes, há uma associação com uma expressiva elevação das taxas informadas da doença entre adolescentes e adultos 21,22

É importante destacar também que, apesar do pequeno percentual correspondente aos

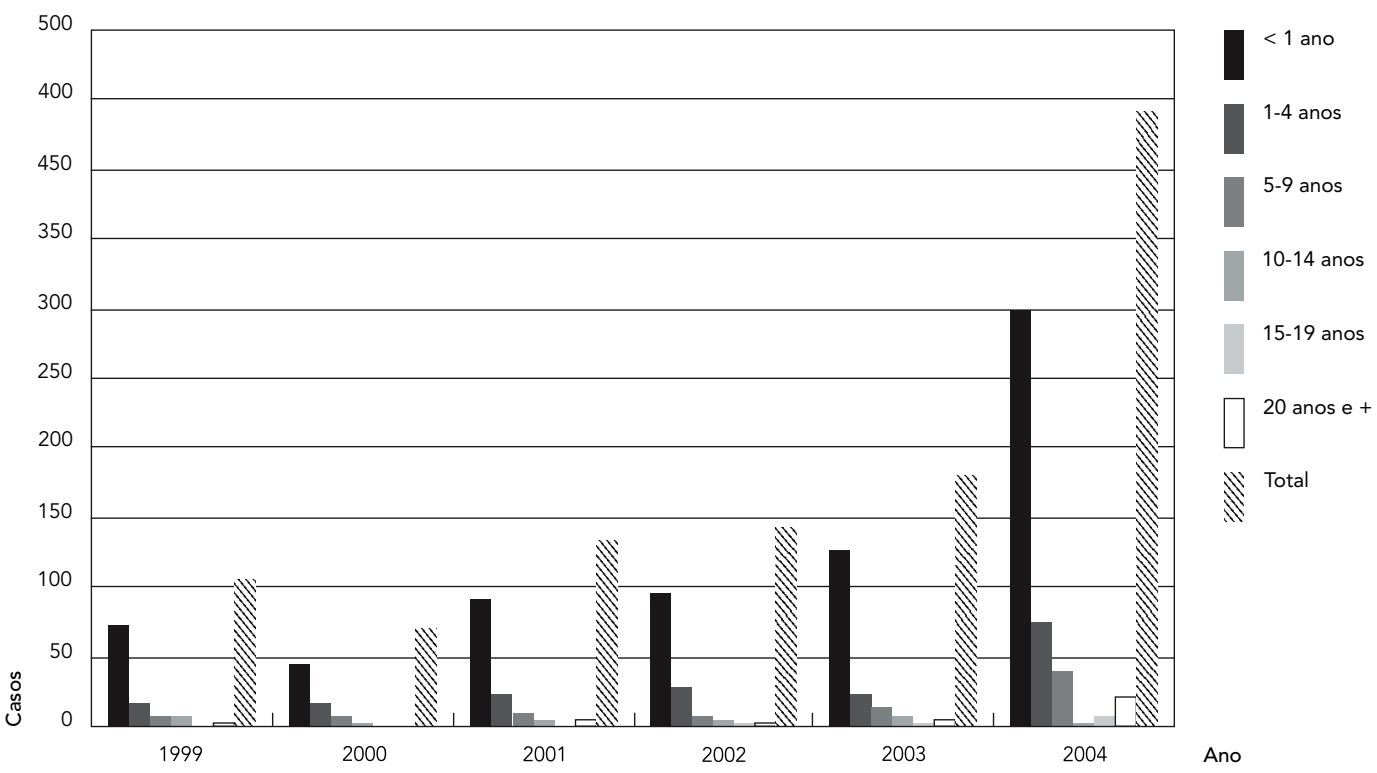

Fonte: Sistema Nacional de Agravos de Notificação (SINAN)/Departamento de Vigilância Epidemiológica/Secretária Estadual de Saúde do Rio Grande do Sul. 
maiores de vinte anos de idade, geralmente eles apenas são diagnosticados, tratados e notificados por serem casos secundários associados à doença em crianças pequenas. Isso reforça a hipótese de haver uma baixa sensibilidade (subdiagnóstico e/ou subnotificação) da rede de assistência para a detecção da doença em crianças maiores e em adultos, uma vez que nestas faixas etárias a doença não se apresenta com os sintomas típicos e exuberantes como quando acomete lactentes, diminuindo assim a busca por recursos de saúde, ou não é considerada no diagnóstico diferencial pelos profissionais da saúde.

Em relação à mortalidade nos últimos anos, verifica-se uma elevação dos óbitos informados em 2003 e 2004, com 4 e 5 mortes, respectivamente (Figura 3). No período de 1997 a 2004, todas as mortes causadas pela doença informadas aos sistemas de vigilância ocorreram em menores de um ano de idade. É possível visualizar na Figura 3 que o aumento do número de óbitos está vinculado às taxas crescentes de coqueluche informadas nos últimos dois anos.

Com base nos dados populacionais informados pelo IBGE 23, do número de casos e óbitos informados pelo Ministério da Saúde/DATASUS e SINAN/Secretária Estadual de Saúde do Rio Grande do Sul, foram calculadas as taxas de incidência para menores de um ano de idade por 100 mil habitantes e os coeficientes de mortalidade para o período de 1997 a 2004. Não foi possível o cálculo dos anos 1995 e 1996 em função de não existirem dados de confirmação de caso neste período no banco de dados do Ministério da Saúde.

Constatou-se que após um período de taxas decrescentes informadas, a partir do ano 2000 a incidência progressivamente aumentou no Rio Grande do Sul, atingindo o valor máximo de 2,3/100 mil habitantes menores de um ano de idade em 2004. Essa incidência está acima da taxa brasileira informada desde 1995, quando o coeficiente de incidência foi de 2,44/100 mil habitantes 10 .

Também verificou-se um acentuado e progressivo aumento do coeficiente de mortalidade no estado a partir do ano 2000, quando nenhum óbito causado pela coqueluche foi informado até o ano de 2004, quando foram registradas cinco mortes pela doença. Isso evidencia que a coqueluche ainda é uma importante causa de mortalidade entre menores de um ano no estado, princi-

Figura 3

Casos confirmados e óbitos por coqueluche. Rio Grande do Sul, Brasil, 1997-2004.

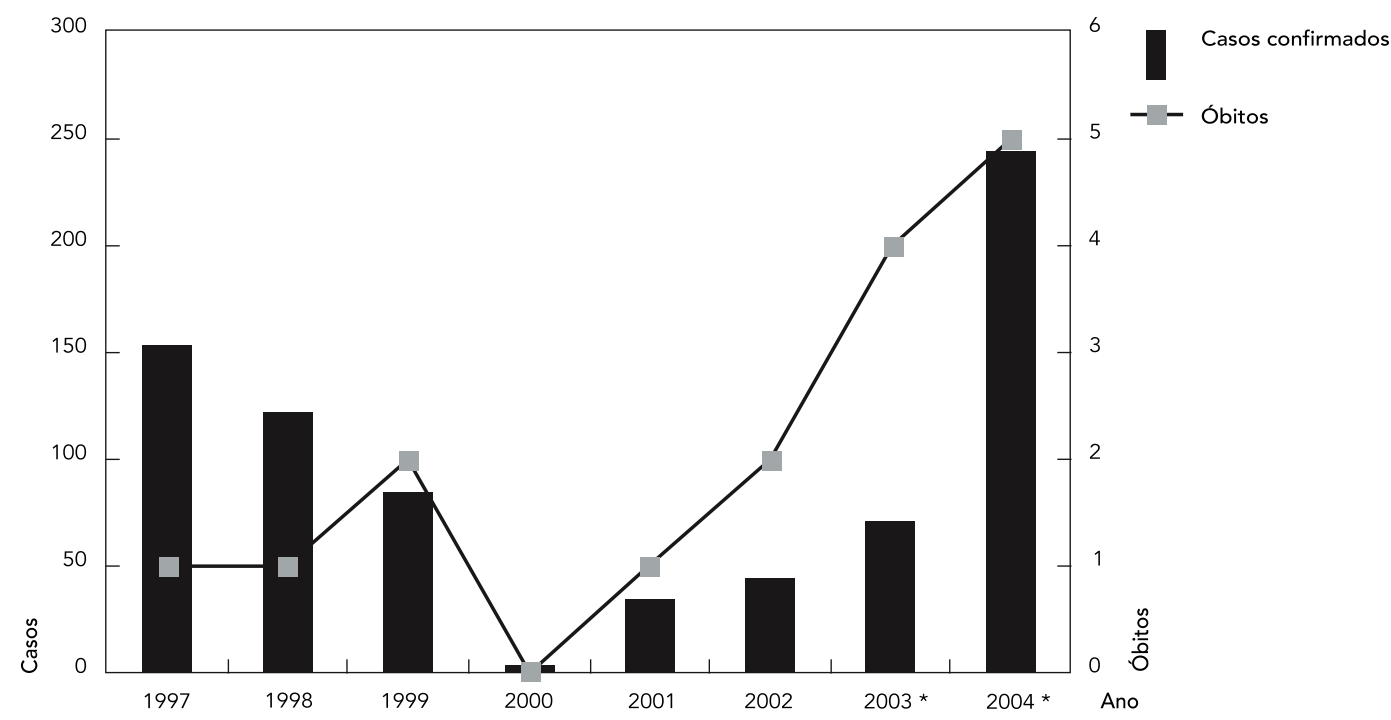

Fonte: Departamento de Análise de Situação de Saúde, Secretaria de Vigilância Sanitária, Ministério da Saúde/Sistema de Informações sobre Mortalidade (SIM).

* Sistema Nacional de Agravos de Notificação (SINAN)/Departamento de Vigilância Epidemiológica/Secretária Estadual de Saúde do Rio Grande do Sul. 
palmente se comparada aos 19 óbitos registrados em todo o Brasil no ano de 2003, último dado informado ${ }^{2}$.

Tratando-se da distribuição sazonal da doença no estado em 2004 (Figura 4), verifica-se que corresponde à tendência descrita na literatura mundial, com maior freqüência de casos durante a primavera e verão.

A partir do conhecimento do número de casos notificados da doença por meses do ano no período de 1995 a 2004, foi construído o diagrama de controle para análise da situação epidemiológica em relação à magnitude do aumento de casos notificados em 2004. Após estabelecida a faixa endêmica, ou seja, a faixa de valores esperados de notificação de casos, foi interpolada a curva de notificação de casos de 2004. Assim, é possível observar na Figura 5 que a partir de fevereiro todos os valores encontram-se acima do limite máximo, indicando que a ocorrência da doença esteve em nível epidêmico.

Quanto aos dados de cobertura vacinal no período de 1995 a 2004, houve pequenas flutuações, mas em geral mantiveram-se em níveis adequados segundo a meta preconizada pelo
Ministério da Saúde de cobertura contra a DTP acima de 90\%, chegando a 98,24\% em 2004.

Numa retrospectiva, durante o período de estudo os anos de 1999, 1997 e 1996 apresentaram os menores percentuais de cobertura e abaixo dos recomendados, com 89,19\%; 84,84\% e $78,53 \%$, respectivamente. Apesar de ocorrer uma certa variação, houve uma elevação na cobertura vacinal a partir do ano 2000, mantendo-se acima dos $90 \%$ até o ano de 2004 .

É importante salientar que, apesar das taxas elevadas de cobertura vacinal, isto não significa que o mesmo percentual de crianças está com o esquema de imunização completo, ou seja, com três doses de vacina contra coqueluche (DTP, DTPa ou DTP + Hib), a partir de dois meses de vida, com intervalo de pelo menos trinta dias entre as doses (o intervalo ideal é dois meses) e com reforço aplicado no prazo de 6 a 12 meses da terceira dose ${ }^{3}$. A importância disso deve-se ao fato de que somente uma dose da vacina não confere proteção contra a doença, sendo necessárias as três doses para induzir proteção adequada.

Contrário à tendência de diminuição de casos frente ao incremento da cobertura vacinal, o que

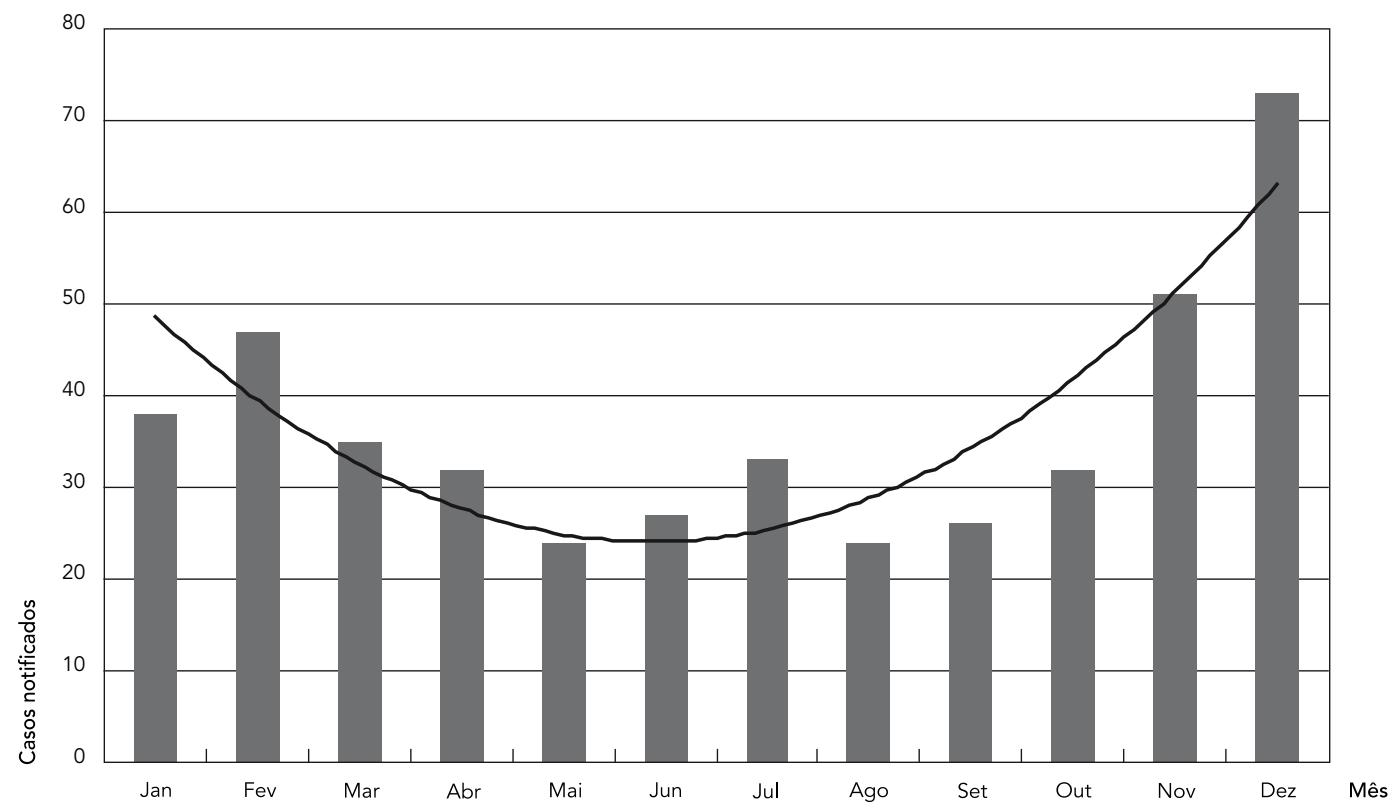

Fonte: Sistema Nacional de Agravos de Notificação (SINAN)/Departamento de Vigilância Epidemiológica/Secretária Estadual de Saúde do Rio Grande do Sul. 


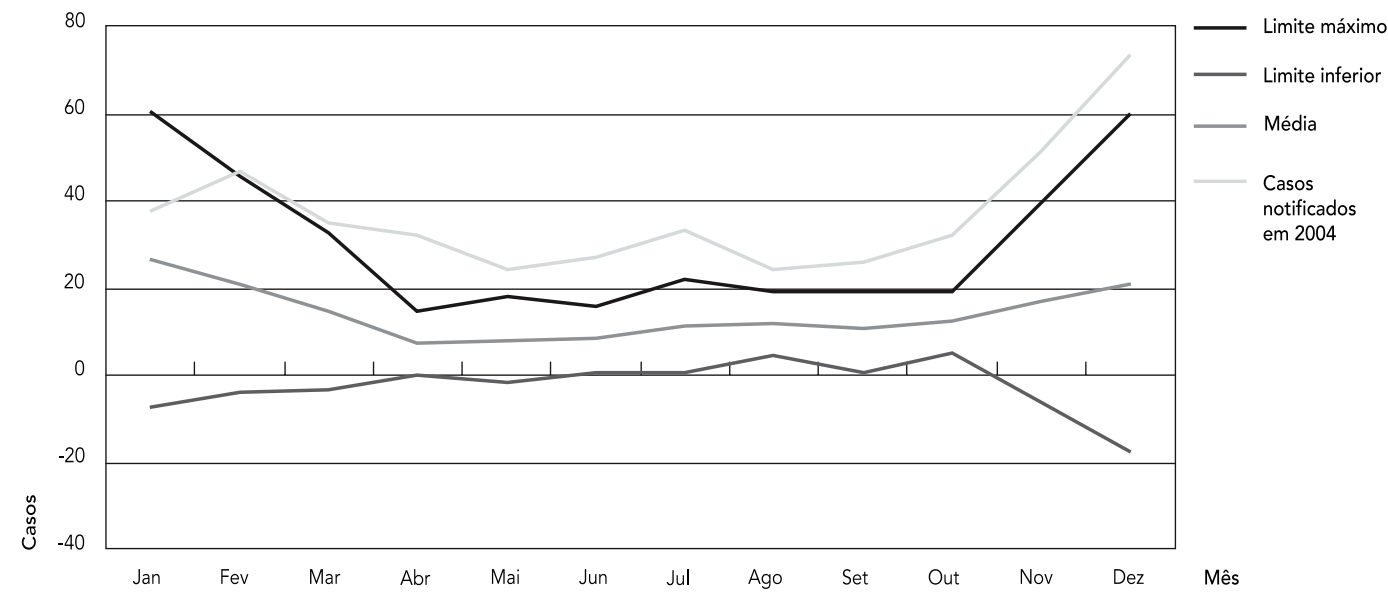

observamos no Rio Grande do Sul é que, apesar dos índices crescentes e elevados de cobertura vacinal, o que se vê é o aumento progressivo da notificação e confirmação de casos a partir do ano 2000, conforme a Figura 6.

Numa prévia do ano de 2005, conforme informado por dados do SINAN/Secretária Estadual de Saúde do Rio Grande do Sul, já se constata que o número de casos notificados e confirmados até a 44a semana epidemiológica manteve-se em níveis elevados, com 360 casos notificados e 122 confirmados de coqueluche.

\section{Discussão}

Apesar da dificuldade na obtenção dos dados arquivados na Secretária Estadual de Saúde do Rio Grande do Sul e pela pouca informação atualizada disponível no DATASUS referentes à coqueluche, com este estudo foi possível caracterizar o perfil epidemiológico no estado. Ao final deste estudo, constatou-se que a coqueluche ainda representa uma causa importante de morbidez e mortalidade em menores de um ano no estado, apesar da disponibilidade de vacinas eficazes e das altas taxas de cobertura vacinal nos últimos anos.

Além disso, a construção do diagrama de controle permitiu estabelecer que para o ano de 2004 a ocorrência da notificação de casos de coqueluche esteve em nível epidêmico, apesar de não ser possível afirmarmos que isto corresponde ao ressurgimento da doença em nosso meio. Isso somente será definido a partir de estudos epidemiológicos do comportamento da doença nos próximos anos, mas este estudo serve de alerta aos sistemas de vigilância responsáveis, instituições e profissionais de saúde, uma vez que foi definida uma situação adversa à normalidade.

Com base nas conclusões deste estudo, há uma forte suspeita de que no Rio Grande do Sul esteja ocorrendo o mesmo padrão epidemiológico informado em países desenvolvidos, cujo aumento do número de casos está vinculado à ocorrência da doença em adultos e adolescentes, decorrente da provável diminuição da imunidade induzida pela vacinação ao longo dos anos. Assim, a circulação da bactéria na comunidade acabaria acometendo o grupo mais vulnerável, qual seja, o das crianças pequenas não imunizadas ou com o esquema incompleto.

Não podemos afirmar que realmente esteja ocorrendo tal mudança no padrão epidemiológico, uma vez que os dados não são atualizados periodicamente pelo sistema de vigilância epidemiológica. No entanto, isso pode estar acontecendo e não sendo identificado pela rede notificadora, pois a principal dificuldade observada na vigilância da coqueluche reside na sua confirmação etiológica. Além disso, a apresentação clínica da coqueluche sofre mudanças induzidas pela vacinação, freqüentemente manifestandose sem os sintomas clássicos e exuberantes, principalmente entre crianças maiores, adolescentes e adultos. 


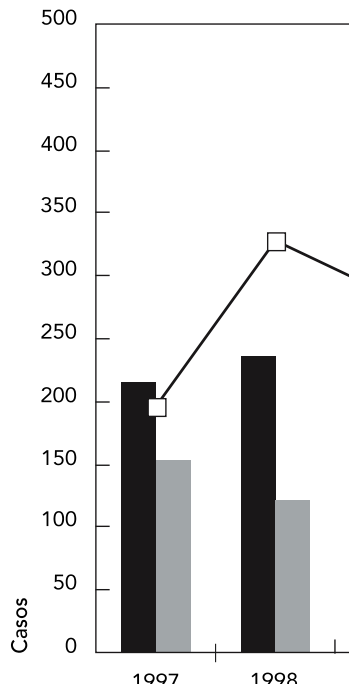

1997 1998
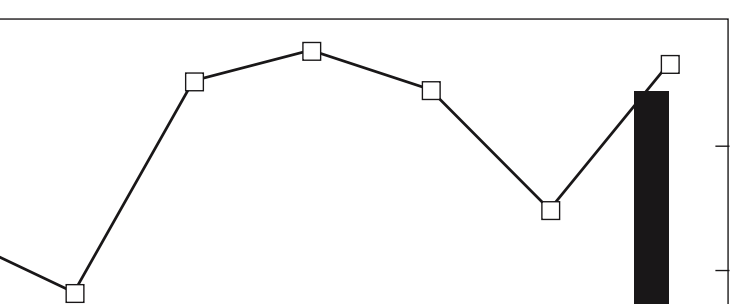

$-95$

$95-\square-$ Cobertura vacinal

00

Casos notificados

Casos confirmados

. 


\section{Resumo}

No Estado do Rio Grande do Sul, Brasil, foi constatado que a coqueluche apresentou uma tendência crescente desde o ano 2000, levando à deflagração de alerta epidêmico em 2004, conforme boletins epidemiológicos emitidos pelos órgãos governamentais de saúde. Nosso objetivo neste estudo foi identificar o perfil epidemiológico da coqueluche nesse estado; para tanto, utilizamos a incidência da notificação da doença entre janeiro de 1995 e dezembro de 2004, a porcentagem de cobertura vacinal e a caracterização da população afetada. Construiu-se um diagrama de controle para determinar a magnitude da doença em 2004; para a análise da correlação entre incidência e cobertura vacinal foi estabelecida a oscilação entre as curvas de cobertura vacinal e de notificação de casos nos últimos dez anos. No Rio Grande do Sul, a coqueluche esteve em nível epidêmico em 2004, representando importante causa de morbimortalidade em crianças menores de um ano, apesar da disponibilidade de vacinas eficazes e de altas taxas de cobertura vacinal informadas nos últimos anos. Portanto, serão necessários estudos sobre o comportamento da doença nos próximos anos e determinação de possíveis fatores envolvidos nesse ressurgimento.

Coqueluche; Cobertura Vacinal; Doenças Transmissíveis

\section{Referências}

1. World Health Organization. Pertussis surveillance: a global meeting. Geneva: World Health Organization; 2001.

2. Ministério da Saúde. Situação da prevenção e controle das doenças transmissíveis no Brasil. Brasília: Ministério da Saúde; 2002.

3. Ministério da Saúde. Doenças infecciosas e parasitárias: guia de bolso. 4a Ed. Brasília: Ministério da Saúde; 2004.

4. Halasa NB, Edwards KM. Is pertussis disease increasing? Int J Epidemiol 2004; 33:365-6.

5. Luz PM, Codeço CT, Werneck GL. A reemergência da coqueluche em países desenvolvidos: um problema também para o Brasil? Cad Saúde Pública 2003; 19:1209-13.

6. Crowcroft NS, Britto J. Whooping cough a continuing problem. BMJ 2002; 324:1537-8.

7. Das P. Whooping cough makes global comeback. Lancet Infect Dis 2002; 2:322.

8. Ouriques RI, Rigatti MFB, Acosta L. A investigação epidemiológica da coqueluche em Porto Alegre. Porto Alegre: Equipe de Controle Epidemiológico, Coordenadoria Geral de Vigilância em Saúde, Secretaria Municipal de Saúde de Porto Alegre; 2005. (Boletim Epidemiológico, 25).

9. Ministério da Saúde. Programa nacional de imunizações 30 anos. Brasília: Ministério da Saúde; 2003.

\section{Colaboradores}

S. Trevizan elaborou o projeto de pesquisa, realizou a coleta e análise dos dados, discussão dos resultados, levantamento bibliográfico e a redação do trabalho. S. E. D. Coutinho participou no delineamento do estudo, levantamento bibliográfico e revisão crítica final do artigo.
10. Ministério da Saúde. Guia de vigilância epidemiológica. 5a Ed. Brasília: Ministério da Saúde; 2002.

11. Departamento de Informática do SUS. Informações de saúde: indicadores de saúde. http://tabnet. datasus.gov.br (acessado em 23/Mai/2005).

12. Equipe de Controle Epidemiológico, Coordenadoria Geral de Vigilância em Saúde, Secretaria Municipal de Saúde de Porto Alegre. Alerta epidemiológico. Porto Alegre: Equipe de Controle Epidemiológico, Coordenadoria Geral de Vigilância em Saúde, Secretaria Municipal de Saúde de Porto Alegre; 2004. (Boletim Epidemiológico, 22).

13. Medronho RA. Epidemiologia. São Paulo: Editora Atheneu; 2004.

14. Meneghel SN, organizador. Caderno de exercícios de epidemiologia. Canoas: Editora Ulbra; 2002.

15. Ministério da Saúde. Curso básico de vigilância epidemiológica: medidas em saúde coletiva e introdução à epidemiologia descritiva. Brasília: Ministério da Saúde; 2003.

16. Pitrez JLB, Pitrez PMC. Coqueluche. In: Pitrez JLB, Pitrez PMC, organizadores. Pediatria: consulta rápida. Porto Alegre: Editora Artmed; 1998. p. 110-1.

17. Forsyth K, Nagai M, Lepetic A, Trindade E. Pertussis immunization in the global pertussis initiative international region: recommended strategies and implementation considerations. Pediatr Infect Dis J 2005; 24(5 Suppl):S93-7. 
18. Centers for Disease Control and Prevention. Guidelines for the control of pertussis outbreaks. Atlanta: Centers for Disease Control and Prevention; 2000.

19. Heininger U. Pertussis: an old disease that is still with us. Curr Opin Infect Dis 2001; 14:329-35.

20. Tozzi AE, Celentano LP, Ciofi degli Atti ML, Salmaso S. Diagnosis and management of pertussis. CMAJ 2005; 172:509-15.
21. Hewlett EL, Edwards KM. Pertussis: not just for kids. N Engl J Med 2005; 352:1215-22.

22. Preston A. Bordetella pertussis: the intersection of genomics and pathobiology. CMAJ 2005; 173:5562.

23. Instituto Brasileiro de Geografia e Estatística. Censo demográfico, 2001. Rio de Janeiro: Instituto Brasileiro de Geografia e Estatística; 2001.

Recebido em 05/Jun/2006

Versão final reapresentada em 04/Abr/2007

Aprovado em 03/Jul/2007 